\title{
XL. Fourth memoir on induction
}

\section{Elie Wartmann}

To cite this article: M. Elie Wartmann (1847) XL. Fourth memoir on induction, Philosophical Magazine Series 3, 31:208, 241-251, DOI: 10.1080/14786444708562636

To link to this article: http://dx.doi.org/10.1080/14786444708562636

册 Published online: 30 Apr 2009.

6 Submit your article to this journal $\pi$

Џll Article views: 4

Q View related articles $₫$ 


\title{
LONDON, EDINBURGH AND DUBLIN \\ PHILOSOPHICAL MAGAZINE
}

\author{
A N I) \\ JOURNAL OF SCIENCE. \\ [TIIRD SERIES.] \\ OCTOBER 184.7.
}

XL. Fourth Memoir on Induction. By M. ElJE WartManN, Professor of Natural Philosophy in the Academy of Geneva*.

[With a Plate.]

[Continued from vol. xxx. p. 272.]

$\$$ XIV. On the Commutators employed to render voltaic currents discontinuous, and to separate currents of induction.

116. $\mathrm{T}$ is exactly a century since a remedy for various ail1 ments was first sought in the electric fluid. The first experiments were made at Geneva by Prof. Jallabert in $174.7 \dagger$. At a later period, when the voltaic battery was invented, its physiological effects were studied, and they are now employed for the cure of various affections, such as obstinate ulcers $t$, dumbness, , deafness $\|$, blindness $\uparrow$, tic-doloureux $* *$, paralysis $\dagger \dagger$, \&c. Lastly, since the discovery of magnetic and electric induction in 1831 by Mr. Faraday, it has been found that the induced currents, as well as the electrical discharges of the Leyden jar, have an extremely short duration, and produce greater shocks than batteries of a large number of elements. The idea therefore has occurred of rendering the current of the electromotor apparatus discontinuous, to approximate it

* Communicated by the Author.

† Expériences sur l'Electricité, p. 127. 8vo. Geneva, 1748.

$\ddagger$ Becquerel, Traité de Physique, vol, ii. p. 638. Paris, 1844 .

$\$$ Namias, De alcuni effetti dell' elettrico sopra l'Animale Economia, \&c., p. 27. Venice, 1841.

|| Giornale per servire ai progressi della Patologia et della Terapeutica. Gennajo, 1843, p. 108 . Giornale delle Scienze Mediche di Torino, vol. iv. p. 430 .

IT Giornale per servire, \&c., December 1841,p. 658. Biblioteca Italiana, fascicolo 25, p. 12, \&cc.

** Zantedeschi, Trattato della Elettricità, vol, ii. p. 525.

tt Giornale di Fisica, \&c. di Pavia, decade II. vol. vii. p. 284 ; and vol. viii. p. 219. Annali delle Scienze del Regno Lombardo-Veneto, January and February 1833, \&c.

Phil. Mag. S. 3. Vol. 31. No. 208. Oct.1847. 


\section{Prof. E. Wartmann's fourth Memoir on Induction.}

to the cases of induced currents. Dr. Neeff of Frankfort on the Maine, in $1835^{*}$, and M. Masson in the following year ${ }^{\dagger}$, have made very conclusive experiments on this subject. An instrument described by $M$. Poggendorff under the name of inversor $\neq$, is intended to render the current of an ordinary battery at the same time discontinuous and in an alternate direction through a given conductor.

117. At the present day the employment of induced currents seems to become more and more general. In place of the original magnets employed in the apparatus of Ritchie $\S$,

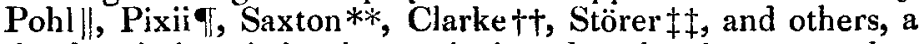
simple voltaic pair has been substituted, and an instrument has been constructed, of small size, easy of transport, and producing almost unlimited effects, called an electro-electric machine, or a shock-machine. M. Bonijol constructs this machine with such perfection that it has been generally adopted, and there is at the present day scarcely an hospital where it is not found. It is employed in the treatment of a multitude of nervous affections; in that of amaurosis $\hat{\oint} \oint$, in assisting parturition \|\|, and as a diagnostic to ascertain the state of vitality of the foetus.

118. I have had more than one opportunity of convincing myself that many persons make use of the shock-machine withont understanding either its construction or its theory. This machine, arranged on a different plan, might be rendered both more intelligible in its mode of action and more useful to the physicist and the physiologist. I will point out some of the cases in which it may be employed, and afterwards the arrangement applicable to each of them.

119. A voltaic current being given, it may be proposed-

1. To render it discontinuous, without changing its direction, in a conductor $\alpha$;

* Das Blitzrad, ein Apparat zu rasch abwechselnden galvaniochen Schliessungen und Trennungen. Pogg. Ann., vol. xxxvi. p. 352, and vol. xlvi. p. 104.

+ Comptes Rendus de l'Acad. des Sciences de Paris, vol.iv. p. 456.

+ Pogg. Ann., vol. xlv. p. 372 and $385 . \$$ Phil. Trans., Oct, 1833.

il Pogg. Ann., vol, xxxiv. p. 185 and 500.

T Ann. de Ch. et de Phys., vol. l.p. 322.

** Phil. Mag. N. S. vol.ix. p. 360.

It Pogg. Ann, vol. lxi. p. 417, 1844.

$\$$ Cunier, Dr., Annales d'Oculistique, vol. xii. end vol. xvi., where will be found a memoir by Dr. Horing On the Employment of the Electro-magnetic rotatory apparatus in Diseases of the Eyes.

III See on this subject, P. Kerz, De electro-magnetsmi vi et usu in arte obstetriciá. Bonn, 1846.-J. A. Schmidtmuller, Handbucḱ der medieinischen Geburtshïlfe.-T. Radford, Galvanism applied to the treatment of uterine Hæmorrhage. Manchester.-Von Kilian, Die Geburtslehre von Soiten der Wissenschaft und Kunst.- Neue zeitschrift fïr Geburtskunde, von H. Bursh, d'Outrepont, \&c., vol, xvi. No, 26, \&c. 
Prof. E. Wartmann's fourth Memoir on Induction. 24.3

2. To render it discontinuous, and in alternately contrary directions.

This current being employed to react on a wire $B$, near the conductor $A$, it may be required-

3. To isolate the direct currents, induced from the closing of the circuit $A$;

4. To isolate the inverted currents, induced on breaking this circuit;

5. To emit these currents successively, giving them the same direction;

6. To emit them alternately in contrary directions, just as they are produced directly.

It is known that there is a reaction of the induced currents on the principal current. We may therefore desire-

7. To collect the totality of their reaction;

8. To avail ourselves only of the reaction of the direct induced currents;

9. To avail ourselves only of that of the inverted induced currents ;

10. 'lo collect only the induction of the inductor on itself.

120. Physicists have studied the majority of these cases; but the mechanical instruments which they have imagined and described under the names of disjunctor *, tachytrope $\uparrow$, rheotrope $\$$, gyrotrope $\oint$, or commutator $\|$, are scarcely applicable except to one or other of the first two categories. The most complete of these instruments, reinvented in Paris seven years after having been described and employed in Germany, is composed of four isolated wheels on the same axis, the outline of which presents successively metallic and ivory arcs, against which press conducting springs. The axis is set in motion by means of a handle or tooth-wheel. Sometimes the interval of the teeth is left void, and the spring in escaping determines the opening of the circuit. Other commutators are formed with needles arranged on isolated axes, in such a manner that one is immersed in mercury at the instant when the other

* Dove, Magneto-elektrischcr Apparat zum Hervorbringen inducirter Ströme gleicher Intensitüt in von einander vollkommen getrennten Drähten Pogg. Ann., vol. xliii. p. 511. 1838.

$\uparrow$ Dove, Ueber den Gegenstrom zu Anfang und Ende eines primären. Pogg. Ann., vol. lvi. p. 25l.

+ Masson et Breguet, Mémoire sur l'induction. Ann. de Ch. et de Phys., vol. iv. p. 134. 1842 .

$\oint$ Pogg. Ann., vol. xxxii. p. 539 ; and vol, xxxiv. p. 185 and 500. $1834-35$.

|| Jacobi, Sar l'application de l'Electro-magnetisme au mouvement des machines, $\$$ VII. Putsdam, 1835. Taylor's Scientific Memoirs, vol. i. p. 503. Archives de l'Electr., vol. iii. p. 244. 


\section{Prof. E. Wartmann's fourth Memoir on Induction.}

comes out of it*. These different systems are complicated, and subject to several inconveniences. The rheotrope, which I shall proceed to describe, and which is especially applicable to electro-electric machines, combines with the advantage of

* On the 18th of June, 1840, I communicated to the Society of Physics and Natural History of Geneva an apparatus of this kind, the construction of which presents no difficulty, and which is deposited in the Cabinet of Physics in the Academy of Lausanne. The following is a description of it:"My commutator is composed of a pure copper stem a b (Plate II. fig. 1), intersected in the middle by a piece of ivory $c$ : the latter is hollowed into the nut of a screw, in such a manner that the two halves of the stem screw into it. Between these metallic extremities some sealing-wax is run, in order to isolate them entirely. The cylinder thus formed is arranged horizontally, and ach of its branches is furnished with symmetrical pieces at equal distances. These pieces are two copper teeth $e f$, placed perpendicularly and at a right angle on the axis ; then a copper circle $g$. Lastly, to one of the extremities of the stem is fixed a pulley $h$, in the groove of which there runs a cord $i$, which again passes over a lower pulley $k$, which is much larger, vertical, and moveable by means of the handle $m$ in one of the supports of the apparatus.

"The six projecting pieces of copper dip intu a glass vessel $n$ (fig. 2), placed on two small horizontal bars $o$; it presents six isolated compartments full of mercury. The extreme circles remain immersed in this liquid during the entire rotation of the stem, the arrangement of the teeth causing one to be immersed whilst the neighbouring one is not. It is easy to regulate the quantity of mercury in the troughs so that the immersion of the one may correspond exactly to the exit of the other.

"Supposing it be desired to emit into a rheometer the two induced currents, giving to them the same direction, it is sufficient to bring the extremities of the wire in which the induction is produced in the extreme compartments reserved for copper circles. The ends of the wire of the multiplicator are tied to bars of copper connecting the troughs $e f$, ef $f$, corresponding on the right and left of the isolator $c$ to the needles fixed at a right angle. So likewise on connecting the extremities of the rheometric wire only with the troughs $f f$, or with the troughs $e e$, it is evident that the direct or inverted induced currents only may be collected.

"I have combined with this arrangement one which M. Bonijol has employed in some of his apparatus. It consists (fig. 3) of planting one of the ends of the stem in a flattened wooden cylinder $r$, on which a spring $s$ presses, passing into a circular cylinder $t$ of hard wood, and the free extremity of which $u$ is placed by the rotation of $r$ in contact with an amalgamated metallic capsule $x$, or is removed from it. Then, by connecting the spring on one side, and the capsule on the other, with the wire which the direct current of the pile traverses, we obtain by the simple rotation of the stern any number of inductions.

"This apparatus enabled me to discover that the thermo electric currents are capable of induction like the hydro-electric currents. I employ a single bismuth-antimony pair, the solder of which is kept at $100^{\circ}$ by steam. The bismuth extremity is connected with the spring $s$, the antimony extremity with a wire covered with silk, which makes seventy turns on a frame, and terminates at the capsule $x$. On the same frame is rolled an isolated and finer copper wire which makes 1200 coils (110.), and both ends of which terminate in the troughs $p q$. The induced citcuit is closed by a very delicate rheometer $(5 a)$, which deviates five degrees and more, 
being more simple, and consequently less subject to derangement, that of not requiring the employment of mercury, and of serving to solve all the cases above stated.

121. H (Plate II. fig. 4) is a reel on which two insulated wires are wound; one the inductor $A$, by which the current of the battery $p n$ is made to pass; the other the induced $B$, intended to become the seat of the currents of induction. Three brass wheels $r, s, t$, of the same diameter, are isolated from one another on a common axis ; their circumference presents an equal number of parts alternately of metal and wood. Two metallic springs $a, b$ are fixed against the wheel $r$, in such a manner that the first leans against a conducting arc, and the other against an insulating arc. The wheels $s$ and $t$ are each pressed by two springs $c d$, ef, similarly arranged. The central metallic parts of the three wheels are in constant communication with the springs $g, h, i$.

122. If it be desired to collect the voltaic current always in the same direction after having rendered it discontinuous, it is sufficient to connect the spring $i$ with the pole $p$ by a wire $\alpha$, and the other pole $n$ with the spring $f$, by means of any conducting wire different from the wires $\mathrm{A}$ and $\mathrm{B}$ wound upon the reel. If it is wanted to obtain, as with the inversor, the discontinuous current in directions alternately contrary, we must join the springs $c$ and $e$ as well as the springs $d$ and $f$, and then connect the extremity of the conjunctive wire of the battery with the spring $h$.

123. When it is desired to employ currents of induction, the contact of the extremity $l$ of the inducting wire with the pole $n$ is established permanently, and that of the extremity $m$ with the spring $f$. Now, to isolate the direct currents induced at the closing of the circuit $A$, we have only to connect the ends $x$ and $y$ of the wire $B$ respectively with the springs $b$ and g.- To isolate the inverted currents, we unite $x$ with $h$ and $y$ with $d .-$ To cause the direct and the inverted currents to pass one after another in the same direction through the rheometer $\mathrm{G}$, for example, we connect the springs $a$ and $c$ with the end $s$ of the wire of the instrument, the springs $b$ and $d$ with the end $t$, the extremity $x$ with the spring $h$, and the extremity $y$ with the spring g.-To collect the induced currents alternately in contrary directions, just as they are produced directly,

when it is traversed by direct and inverted currents in the same direction." (See the Transactions of the Helvetic Society of Natural Sciences for 1840 , pp. 173, 195.)

Prof. Dove has demonstrated thermo-electric induction by a different process. His researches were made at the same time as mine, and in an independent manner. (See Pogg. Ann., vol. xlix. p. 97. 1840.) 
we disconnect the extremities $x$ and $y$ of the wire B from the springs of the rheotrope.

124. Lastly, if we propose to employ the reaction of the induced wire $B$ on the inductor $A$, and that of the inductor wound in a helix on itself, we substitute for the wire $\alpha$ the body which is to be subjected to the effects of these reactions. We then employ one of the four arrangements above described (123.), according as we wish to obtain the totality of influence of the two currents induced in the sanre direction, or in directions alternately opposed, or again, the separate influence of the direct or the inverted currents. The simple induction of the inductor on itself is obtained with a reel with a single wire in place of the conductor $\alpha$, and the arrangement described (122.).

125. It remains for me to give some details on the construction of the rheotrope. The three metallic wheels $r, s, t$ (fig. 5) present on their periphery twelve hollows filled in with hard wood. These heterogeneous wheels have been worked together by the lathe; they are each $0^{\mathrm{m} \cdot 80}$ in diameter, and $0^{\mathrm{m} \cdot 06}$ in thickness. A metallic tooth of the middle wheel $s$ exactly corresponds to one isolating part of the extremes $r$ and $t$. They are placed on the same brass axis $k l$, which is turned by a winch $n$ or a tooth-wheel. The spring $i$ and the wheel $t$ are in metallic contact with the axis. The wheels $r$ and $s$ are, on the contrary, each isolated from it by an ivory ring covered externally with a brass cylinder. These two cylinders bear the wheels, and are constantly pressed by springs $g, h$, which embrace them on a semi-circumference. The three springs $g, h, i$ terminate on the three heads $g^{\prime}, h^{\prime}, i^{\prime}$, by means of which they can communicate together. Lastly, the six springs $a, b, c, d, e, f$ are made of plates of hammered copper; they are fixed to the base of the instrument by screws, $r^{\prime}, s^{\prime}, t^{\prime}$, the heads of which, similar to $g^{\prime}$, and pierced like them with two holes, can receive the metallic wires intended to establish a connexion between the different wheels. These springs are cleft in order that the groove may facilitate the adjustment of their length. Above they bear a screw (fig. 6) in the part which has to rest on the circumference of the wheels; the opposite rotch allows of regulating the elasticity of the spring and the degree of friction. The play of these pieces may thus be regulated with minute precision.

126. If it is not wanted to impart the same direction to the two induced currents, the apparatus may be simplified by giving it only two wheels. One is reserved to render the current of the battery intermittent; the other is joined to the induced wire; and according as there is coincidence or alter- 
nation in the closing of the two circuits, only either the direct or the inverted currents are received. This double effect may be obtained by changing the point of contact with one of the springs, or by varying the position of one of the wheels on the axis relatively to the other. Two wheels do not permit of giving the same direction to the direct and the inverted currents; because as it is evident that the induced circuit must communicate with the two wheels when the principal current is closed, a part of this current may proceed from the wire of induction and modify the effect of the direct induced current.

127. Lastly, if it be desired to isolate only the inverted induced currents, the rheotrope may be reduced to a single wheel. It is sufficient for the proposed object to open the induced circuit when the inducting circuit is closed, and vice versâ. But this arrangement would not be suited to isolate the direct induced currents, because it would be necessary to close simultaneously the two circuits, and the voltaic current would be propagated in the double channel presented to it.

128. It will be found convenient to mark letters on the different pieces $g^{\prime}, h^{\prime}, i^{\prime}, r^{\prime}, s^{\prime}, t^{\prime}$, and to repeat them at the extremities of the metallic conductors employed to connect these pieces. These conductors will be fixed to the interior of the lid of the case which contains the whole electro-electric machine; and a brief direction will indicate which ought to be employed to produce the effects corresponding to the different possible cases.

129. It is understood that the commutator with three or with two wheels is applicable to all magneto-electric machines, telegraphs, clocks, \&c., whose motive principle is the electricity of the magnet or of the battery.

\section{$\oint \mathrm{XV}$. Employment of induced currents to restore sensation.}

130. The cases of nervous weakness which have yielded to a judicious application of electro-physiological shocks and discharges are too well ascertained to admit of any question. Since the marvellons effects of ather have been known, I have proposed to several physicians the employment of the electroelectric machine, or at least of intermittent currents of very short duration, to obviate the dangers which the injection of too strong a dose of this liquid, or a too prolonged inhalement of it, might produce. I have made some experiments* with a view to verify the accuracy of my expectations; and although they are so few as to require to be repeated and varied, I shall

* In company with Di. A. P. Prevost, and Mr. Schnetzler. I take this opportunity of thanking these gentlemen for their zealous cooperation. 


\section{Prof. E. Wartmann's fourth Memoir on Induction.}

give them here, because similar results have recently been announced by M. Ducros*.

131. The animals subjected to experiment were a rabbit three months old, a chicken nine months old, and some frogs of both sexes. They are all very sensitive to electric shocks. The action of æther upon them is also very powerful, especially on the frogs, which should not be moistened with this liquid.

132. The rabbitand the chicken appeared to have recovered their sensation sooner under the influence of the shocks of induction than by simple exposure to the air. In the frogs no difference in this respect was remarked.

133. The ætherization was effected by plunging the animal into a glass cylindrical vessel, in which boxes were arranged furnished with sponges moistened with ather; it was covered with a piece of linen dipt in water. The internal atmosphere was removed from time to time by removing the covering.

134. The most remarkable case was presented by the chicken. A quantity of æther, more than sufficient to produce insensibility, was injected into its rectum. When it arrived at this state, two or three shocks of the electro-electric apparatus (110.) were passed from one wing to the opposite leg, which shocks were effected by a Grove's pair; immediately the eyes opened. On continuing the discharges in a very intermittent manner, the animal was seen to struggle, to rise on its feet, and then to fly to the end of the laboratory, relapsing gradually into an insensible sleep under the influence of the portion of injected æther which had not as yet produced its effect.

135. The rabbit and the chicken were subjected to several successive æetherizations. The former, young and weak, died six or seven hours after the fourth trial (injection). At the end of fifteen hours its body was stiff, as if death had resulted from natural causes. Its nerves exhibited the softening mentioned by some anatomists. The chicken, on the contrary, survived, and even on the following day laid an egg with a soft shell. It subsequently produced several others perfectly healthy. It did not appear to feel the effects of the shocks or injections to which it had been subjected. It ate corn greedily, and the rabbit lettuce leaves, as soon as the stupefaction produced by the æther had terminated.

136. Experiments were made on the frogs and the chicken; one while with the effect of the induced currents successively

* Comptes Rendus de l'Académie des Sciences de Paris, sitting of the 22nd of February 1847, p. 286. 
Prof. E. Wartmann's fourth Memoir on Induction. 249

direct and inverted, at another with inverted currents only, employing the arrangement above described (127.). There was no perceptible difference between the two methods of electrifying, even on circulating the inverted currents from the feet to the wings, or vice versâ.

\section{$\oint$ XVI. Action of Induced Currents on Albumen.}

137. Brande was the first who pointed out the coagulation of albumen on the positive pole of the battery. M. Matteucci, in treating of the physiological action of electric currents*, says, that if the pole which was first positive be rendered negative, the albumen is not seen to redissolve, and that consequently an electric current may very well produce a cataract, but not destroy it. On the other hand, Prof. Zantedeschi affirms that he has seen the liquefaction of the albumen at the negative pole $\uparrow$. Repeated experiments have never shown me this return to the fluid state, and lead me to adopt entirely the conclusion of the celebrated physiologist of Pisa.

138. The coagulation of albumen does not present any remarkable phase, when, under the immediate influence of a battery, we substitute either direct or inverted induced currents, or the voltaic current rendered intermittent and strengthened by the reaction of the induction which it has engendered in its own conductor and in the neighbouring conductor (124.). But the phænomenon changes when the liquid is traversed by induced currents in alternate directions.

139. Through the inducting wire $A$ of an electro-electric machine furnished with a bundle of iron wires, I passed the current of five Grove's pairs of $0^{\mathrm{m} \cdot 1}$ square surface. The extremities $x$ and $y$ of the induced wire $B$ (fig. 7) terminated in cups $g g$ full of mercury. The circuit was closed by two platina wires $a, b$ of $1 \mathrm{~mm}$ in diameter, one part immersed in the cups, the other in the glass $o$ full of the white of egg. The latter immediately coagulated around each wire, especially round that which communicated with the extremity of the circuit $\mathrm{B}$, from whence proceeded the inverted induced current, and which corresponded to the positive termination of the rheophorus A. At the end of a few ninutes some bubbles of gas appeared on the circumference of the coagulum. Some, having increased in volume, rose lightly to the surface of the viscous medium in which they were formed. The albumen, riddled with holes, by which the gas escaped and continued 1844.

* Lezioni sopra i fenomeni fisico-chimici dei corpi viventi, p. 173. Pisa, + Trattato del Magnetismo et della Elettricità, vol. ii. p. 511. Venice, 1845 . 


\section{Prof. E. Wartmann's fourth Memoir on Induction.}

to be disengaged, turned black in several places: then a series of luminous sparliles, and lastly real sparks of a bright yellow glittered on the whole immersed part of the platina wire. At the same time the induced wire B was heated around the reel, the metallic pieces of the rheotrope rose in temperature, and the upper sides of the glass, not filled with the albumen, were coated with aqueous vapour.

140. This remarkable phænomenon is doubtless complicated. The coruscations do not dart from one wire to the other in the liquid; they are seen along the wire. I thought at first that the combustion (for it was such) only took place on one of the electrodes (139.); but on repeating the experiment many times, $I$ saw it alternate on both of them according as $I$ reversed the poles of the battery, or present itself first upon one wire, then upon the other, without the direction of the current being changed; or lastly appear upon only one of them, whatever changes were made in the positions of the rheophori and the extremities of the induced circuit. I attribute this latter case, which only occurred when the surface of the albumen was covered with a layer of æther, to the difference of the conditions of contact of the two platina electrodes with the liquid: one, in fact, was then only covered with a slight coagulum, whilst the other gave rise to a considerable quantity of gas. These gases were collected on the æther in a tube traversed by a platina wire cemented at its top. They presented neither free carbonic acid, nor oxygen, nor hydrogen. I think that they were a mixture of oxide of carbon and carburetted hydrogens.

141. The albumen solidified around platina conductors acquires the consistence of very soft glue; it is ductile, brownish, even blackish, and diffuses a marked odour of burnt horn or phosphoretted hydrogen. The platina does not take the pulverulent appearance nor black colour which are communicated to it by discontinuous alternate currents in other media ; it preserves its metallic appearance. With the assistance of Prof. Marignac I analysed the coagulum; it contained no trace of platina. There is therefore here no catalytic action.

142. These various remarks lead me to think that, in circumstances of imperfect conductibility of the albumen, and of great power in the induced currents employed, the immersed wires become heated when the coating of coagulum and of gaseous bubbles has put a new obstacle to the passage of the alternate currents (an obstacle rendered evident by the elevation of temperature of the external circuits), whence results a true igneous decomposition and a burning, under the influence of oxygen in a nascent state, of combustible elements exposed. 
143. Whatever value this opinion may have, it seems to me that the decomposition of albumen by the passage of very intense induced currents is a fact which deserves the serious attention of physicians and physiologists. The presence of this body in the blood, in urine, in the eye, in amniotic liquors, \&c., requires caution in the employment of violent alternate currents.

144. The appearances which I have described equally take place in the albumen extracted from new-laid eggs, imnersed for some hours in the vapour of æather. They appear even to be developed there more easily.

145. It is perhaps well to add, that the production of these bright coruscations indifferently on the two electrodes negatives any explanation founded on a different polarity of the platina wires, and all analogy with the phænomena investigated by MM. Gassiot*, Hare $\uparrow$, and Neeff $\ddagger$.

Geneva, June 18, 1846.

\section{On eliminating the Signs in Star-Reductions. By S. M. Drach, F.R.A.S.}

To the Editors of the Philosophical Magazine and Journal. Genthemen,

THE subject of this paper was broached by the Astro1 nomer Royal in the Monthly Notices of the Royal Astronomical Society for January 1847. I beg to propose the following extension, eliminating even the indices of the logs. employed.

Let $\mathrm{A}=\mathrm{E}-\mathrm{P}, \mathrm{B}=\mathrm{F}-\mathrm{Q}, \mathrm{C}=\mathrm{G}-\mathrm{R}, \mathrm{D}=\mathrm{H}-\mathrm{S}$; $a=e-p$, \&c. $a^{\prime}=e^{\prime}-p^{\prime}$ for decl., or $=p^{\prime}-e^{\prime}$ for N. P. Dist., $\mathrm{P}, p, p^{\prime}, \& c$. are numerical constants afterwards determined.

Corr. R.A. $=\Sigma \mathrm{A} a=\Sigma \mathrm{E} e-\Sigma e \mathrm{P}-\Sigma \mathrm{E} p+\Sigma \mathrm{P} p$ :

Corr. N.P.D. $=\Sigma \mathrm{A} a^{\prime}=\Sigma \mathrm{E} e^{\prime}-\Sigma e^{\prime} \mathbf{P}-\Sigma \mathrm{E} p^{\prime}+\Sigma \mathrm{P} p^{\prime}$.

Let $\mathrm{P}=28 \cdot 75, \mathrm{Q}=30.5, \mathrm{R}=1.35, \mathrm{~S}=20$ (R.A. given in time).

I. Right ascension, $p=2^{\mathrm{s}}, q=2, r=30 \cdot 5, s=2$.

* Archives de l'Electricit'́, vol. iii. p. 240.

+ Silliman's American Journal, January 1841. I succeeded several years ago in melting in an intermittent manner an iron wire of $2^{\mathrm{mm}}$ diameter, employed as a negative electrode on the surface of impure mercury in which a copper wire bound to the positive pole is immersed. Twenty Daniell's couples, or forty smaller Bunsen's, suffice for this experiment.

$\ddagger$ Archives des Sciences Physiques et Naturelles, vol. i. p. 30. 